\title{
Impact of radiation therapy on breast-conserving therapy for breast cancer in Japanese women: A retrospective analyses of multi-institutional experience. Kansai Breast Cancer Radiation Therapy Study Group
}

\author{
MICHIHIDE MITSUMORI ${ }^{1}$, MASAHIRO HIRAOKA ${ }^{1}$, HIDEO INAJI $^{2}$, SHINZABURO NOGUCHI $^{3}$, \\ HAJIME OISHI $^{4}$, HIROSHI KODAMA ${ }^{5}$ and HIROKI KOYAMA ${ }^{2}$
}

\begin{abstract}
${ }^{1}$ Department of Radiation Oncology and Image-Applied Therapy, Graduate School of Medicine, Kyoto University, 54 Kawahara-cho, Shogoin, Sakyo-ku, Kyoto 606-8507; ${ }^{2}$ Department of Surgery, Osaka Medical Center for Cancer and Cardiovascular Diseases, 1-3-3 Nakamichi, Higashinari-ku, Osaka 537-8511; ${ }^{3}$ Department of Surgical Oncology, Osaka University Graduate School of Medicine, 2-2 Yamada-oka, Suita, Osaka 565-0871;

${ }^{4}$ Nara Health Promotion Center, 404-7 Miyako, Tawaramoto-cho, Shiki, Nara 636-0300;

${ }^{5}$ Kodama Breast Clinic, 35 Kitano-Kamihakubai-cho, Kita-ku, Kyoto 603-8325, Japan
\end{abstract}

Received December 12, 2008; Accepted February 17, 2009

DOI: 10.3892/or_00000375

\begin{abstract}
Whole breast radiation therapy (RT) after breastconserving surgery is sometimes omitted in Japan; however, its impact on the outcome has not been properly evaluated. A multi-institutional retrospective study was conducted to clarify the impact of RT on local control after breast-conserving therapy (BCT). Data were collected from 3576 patients from 37 participating hospitals, of whom 1763 were eligible for analyses. Five hundred and five patients had ipsilateral breast tumor recurrence (IBTR) and 1258 patients did not. Details of IBTR were available for 245 of 505 patients who had IBTR, the location of IBTR was within or adjacent to the original tumor bed in 168 patients $(68.6 \%)$. IBTR was salvaged with partial mastectomy in 119 patients $(48.6 \%)$. Second recurrence in the ipsilateral breast was observed in 27 patients $(11.0 \%)$. Univariate analyses demonstrated that administration of RT, the resection margin status, hormone responsiveness, $\mathrm{T}$ stage, $\mathrm{N}$ stage and stage were significantly related to IBTR. Multivariate analysis demonstrated that administration of RT, T stage and $\mathrm{N}$ stage were significantly correlated to IBTR. Among them, administration of RT had the largest impact on RT and it decreased the risk of IBTR by $77.3 \%$. Omission of RT had the most significant impact on IBTR. RT should be given as a standard component of BCT.
\end{abstract}

Correspondence to: Dr Michihide Mitsumori, Department of Radiation Oncology and Image-Applied Therapy, Graduate School of Medicine, Kyoto University, 54 Kawahara-cho, Shogoin, Sakyo-ku, Kyoto 606-8507, Japan

E-mail: mitsumo@kuhp.kyoto-u.ac.jp

Key words: breast cancer, breast-conserving therapy, radiation therapy, ipsilateral breast recurrence

\section{Introduction}

The incidence of breast cancer in Japanese women has become the highest among various cancers and it was estimated that 40675 women were newly diagnosed with breast cancer in 2001. The ratio of patients who undergo breast-conserving surgery (BCS) is also increasing and BCS has become the most frequently employed method of initial surgery for breast cancer in Japan (1). According to the NIH consensus statement, breast-conserving therapy (BCT) comprises of BCS and adjuvant radiation therapy (RT). The role of RT in BCT has been well established as a result of at least 8 randomized controlled trials and meta-analyses of these trials (2-10). Moreover, the subgroup of patients who do not receive a benefit from RT after BCS has not been defined in spite of various attempts to find such a subgroup. In Japan, however, 20\% of patients who undergo BCS do not receive RT (1). This number is larger than in the USA (11). One reason for not receiving RT in Japan is that some surgeons believe that RT is not necessary if the tumor was resected with an ample pathologically negative margin and that RT is harmful and deteriorates the cosmetic outcome. To clarify the impact of RT on ipsilateral breast tumor recurrence (IBTR) in such practice in Japan, we collected data from participating institutions of the Kansai Breast Cancer Radiation Therapy Study Group (KBCRTSG) and analyzed them retrospectively.

\section{Patients and methods}

Study design. This study was conducted as a multi-institutional retrospective review. The primary endpoint was IBTR, including those preceded by any form of regional and distant recurrence.

Patients. Between August 2004 and February 2005, data from 3576 patients were collected from 37 participating hospitals in 
Table I. Patient characteristics.

\begin{tabular}{|c|c|c|c|}
\hline & $\begin{array}{l}\text { Patients } \\
\text { with } \\
\text { IBTR } \\
(n=505)\end{array}$ & $\begin{array}{c}\text { Patients } \\
\text { without } \\
\text { IBTR } \\
(n=1258)\end{array}$ & P-value \\
\hline Age & $49.8 \pm 12.2$ & $49.8 \pm 9.9$ & N.S. \\
\hline Method of surgery & & & $\mathrm{P}=0.082$ \\
\hline Quadrantectomy & 129 & 211 & \\
\hline Wide excision & 362 & 572 & \\
\hline Tumorectomy & 8 & 3 & \\
\hline Other & 0 & 2 & \\
\hline Unknown & 6 & 470 & \\
\hline T stage ${ }^{\mathrm{a}}$ & & & $\mathrm{P}=0.017$ \\
\hline T0 & 4 & 0 & \\
\hline $\mathrm{T} 1$ & 169 & 402 & \\
\hline $\mathrm{T} 2$ & 153 & 256 & \\
\hline T3 & 3 & 1 & \\
\hline Unknown & 176 & 599 & \\
\hline N stage ${ }^{a}$ & & & $\mathrm{P}=0.000$ \\
\hline NO & 193 & 570 & \\
\hline N1 & 121 & 159 & \\
\hline $\mathrm{N} 2$ & 26 & 15 & \\
\hline N3 & 0 & 1 & \\
\hline Unknown & 165 & 513 & \\
\hline Stage $^{a}$ & & & $\mathrm{P}=0.000$ \\
\hline Stage 0 & 5 & 0 & \\
\hline Stage 1 & 142 & 349 & \\
\hline Stage $2 \mathrm{a}$ & 119 & 233 & \\
\hline Stage $2 b$ & 73 & 71 & \\
\hline Stage $3 a$ & 27 & 7 & \\
\hline Unknown & 139 & 658 & \\
\hline Margin status & & & $\mathrm{P}=0.000$ \\
\hline$>5 \mathrm{~mm}$ & 302 & 750 & \\
\hline$\leq 5 \mathrm{~mm}$ & 139 & 219 & \\
\hline Unknown & 63 & 289 & \\
\hline Hormone receptor stastus & & & $\mathrm{P}=0.000$ \\
\hline Positive & 236 & 715 & \\
\hline Negative & 184 & 289 & \\
\hline Unknown & 85 & 254 & \\
\hline Radiation therapy & & & $\mathrm{P}=0.000$ \\
\hline Yes & 356 & 1146 & \\
\hline No & 148 & 69 & \\
\hline Unknown & 1 & 43 & \\
\hline
\end{tabular}

IBTR, Ipsilateral Breast Tumor Recurrence. ${ }^{\mathrm{a}}$ General rules for clinical and pathological recording of breast cancer. 14th edition, The Japanese Breast Cancer Society.

KBCRTSG. The data format was developed by the steering committee of KBCRTSG and includes patient characteristics, including clinicopathological findings, method of BCT and outcome.
Table II. Details of IBTR.

Patients with detailed

information of IBTR $(n=245)$

\section{Location of IBTR}

$\mathrm{TR} / \mathrm{MM}^{\mathrm{a}}$

Other than TR/MM

Unknown

$168 \quad 68.6 \%$

$65 \quad 26.5 \%$

$12 \quad 4.9 \%$

Type of IBTR

Nodular

209

$85.3 \%$

Diffuse

32

$13.1 \%$

Nodular/diffuse

3

$1.2 \%$

Method of salvage

Partial mastectomy

$119 \quad 48.6 \%$

With RT

$36 \quad 14.7 \%$

Total mastectomy

$4.7 \%$
$41.6 \%$

With RT

102

Unknown surgery

$1.2 \%$

With RT

No surgery

With RT

$2.4 \%$

$0.8 \%$

$7.3 \%$

$0.8 \%$

Re-IBTR

$\begin{array}{lll}\text { No } & 193 & 78.8 \%\end{array}$

Yes $\quad 27 \quad 11.0 \%$

Unknown $\quad 25 \quad 10.2 \%$

${ }^{a}$ True recurrence/marginal miss: Recurrence within or adjacent to original tumor bed.

Eligibility criteria for this study were as follows: i) Japanese female, ii) received $\mathrm{BCS}$ alone or $\mathrm{BCT}$, including $\mathrm{RT}$, at participating hospitals of KBCRTSG, iii) has outcome data regarding both local and systemic control and iv) longer than 5-year follow-up for patients without IBTR.

Thus, 1813 cases without IBTR were excluded due to shorter follow-up than 5 years. Consequently, 505 cases of IBTR and 1258 cases of no IBTR were subjected to further analyses. Of note, 173 of the former and 70 of the latter had distant metastasis in their disease course. Patient characteristics are shown in Table I.

Statistical analyses. Univariate and multivariate Cox regression analyses were used to evaluate the impact of patient and treatment factors on the endpoint. Pearson's Chi-square test was used to evaluate the distribution of the patients' background. A p-value of $<0.05$ was regarded as significant.

\section{Results}

Details of IBTR were available for 245 of 505 patients with IBTR (Table II), the location of IBTR was within or adjacent to original tumor bed in 168 patients $(68.6 \%)$, in another location in 65 patients $(26.5 \%)$ and unknown in 12 patients $(4.9 \%)$. The type of IBTR was nodular in 209 
Table III. Univariate analyses.

\begin{tabular}{|c|c|c|c|c|}
\hline & No. of available patients & $\mathrm{RR}$ & 95\% C.I. & P-value \\
\hline Age & 1748 & 1.011 & $1.003-1.020$ & $\mathrm{P}=0.006$ \\
\hline Radiation therapy & 1722 & 0.276 & $0.229-0.333$ & $\mathrm{P}=0.000$ \\
\hline T stage & 986 & 1.391 & $1.121-1.725$ & $\mathrm{P}=0.003$ \\
\hline $\mathrm{N}$ stage & 1085 & 1.808 & $1.503-2.174$ & $\mathrm{P}=0.000$ \\
\hline Stage & 1032 & 1.328 & $1.178-1.498$ & $\mathrm{P}=0.000$ \\
\hline Margin status & 1390 & 1.471 & $1.194-1.812$ & $\mathrm{P}=0.000$ \\
\hline Hormone receptor status & 1424 & 0.593 & $0.487-0.721$ & $\mathrm{P}=0.000$ \\
\hline Method of surgery & 1309 & & & \\
\hline Method (1) quadrantectomy & & $90.410^{\mathrm{a}}$ & $0.000-5.95 \times 10^{17}$ & $\mathrm{P}=0.808$ \\
\hline Method (2) wide excision & & $205.605^{\mathrm{a}}$ & $0.000-1.35 \times 10^{18}$ & $\mathrm{P}=0.774$ \\
\hline Method (3) lumpectomy & & $612.053^{\mathrm{a}}$ & $0.000-4.04 \times 10^{18}$ & $P=0.730$ \\
\hline
\end{tabular}

aRelative risk against method (4) 'other method'.

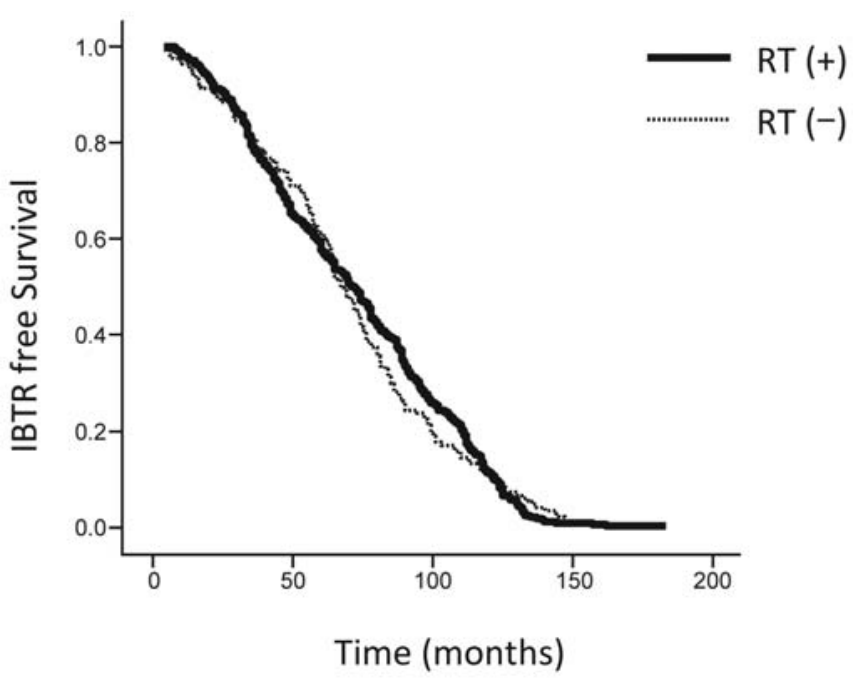

Figure 1. Kaplan-Meier estimate of ipsilateral breast tumor recurrence (IBTR)-free survival of the patients who eventually had IBTR. Note that the rate of IBTR is fairly consistent through 10 years.

patients $(85.3 \%)$, diffuse/inflammatory in 32 patients $(13.1 \%)$ and a combination of these in 3 patients $(1.2 \%)$. IBTR was salvaged with partial mastectomy in 119 patients (48.6\%), total mastectomy in 102 patients (41.6\%), unknown surgery in 6 patients $(2.4 \%)$ and no surgery in 18 patients $(7.3 \%)$, of whom radiation therapy was used as a component of salvage therapy in $36(14.7 \%), 3(1.2 \%), 2(0.8 \%)$ and 2 $(0.8 \%)$. Second IBTR was observed in 27 patients $(11.0 \%)$. Univariate analyses demonstrated that the administration of $\mathrm{RT}$, resection margin status, hormone responsiveness, $\mathrm{T}$ stage, $\mathrm{N}$ stage and stage were significantly related to IBTR. Univariate analyses demonstrated that the administration of $\mathrm{RT}$, resection margin status, hormone responsiveness, $\mathrm{T}$ stage, $\mathrm{N}$ stage and stage were significantly related to IBTR (Table III). The test for correlation among these variables demonstrated that several variables are dependent on each other (Table IV). Among them, stage was strongly correlated to $\mathrm{T}$ stage and $\mathrm{N}$ stage; therefore, $\mathrm{RT}$, resection margin status, hormone responsive-ness, $\mathrm{T}$ stage and $\mathrm{N}$ stage were employed as variables for multivariate analysis using the Cox regression model. This demonstrated that RT, T stage and N stage were significantly correlated to IBTR. Among them, administration of RT had the largest impact on RT and decreased the risk of IBTR by $77.3 \%$ (Table V).

The IBTR-free survival curve was plotted for patients who eventually developed IBTR (Fig. 1). It revealed that the risk of IBTR is fairly constant over time both for patients who received RT and patients who did not.

\section{Discussion}

Several factors may influence the risk of local recurrence after BCT. Among them, administration of RT has been shown to have a large impact on local control, as shown in this study. According to a meta-analysis by EBCTCG, the effect of RT after BCS is highly consistent and reduces the risk of isolated IBTR by $\sim 70 \%$ compared to those allocated to no RT (5). Other factors which are known to increase the risk of IBTR include young age, positive resection margin and existence of EIC.

There have been continuous efforts to identify a subgroup of patients for whom RT after BCS can be safely omitted. In the Joint Center for Radiation Therapy at Harvard Medical School, women considered to be at low risk for IBTR were prospectively observed without RT after BCS. The patients in this study had pT1N0 tumor, absence of both lymphovascular invasion and extensive intraductal component and no cancer cells within $1 \mathrm{~cm}$ of resection margins. This study was terminated before it reached accrual goal because of an excessive number of IBTR. Of note, there were no eligibility limitations on patient age for this study and these patients did not receive any adjuvant chemo-endocrine therapy regardless of the status of hormone receptors (12). Considering that young age is a known risk factor for IBTR (13-19) and that systemic adjuvant therapy provides a benefit for local control $(20,21)$, some patients in this study may not have been at low risk for IBTR. Previously, the CALGB C9343 trial demonstrated that it is a realistic choice for the treatment of 
Table IV. Correlation coefficient among factors analyzed.

\begin{tabular}{|c|c|c|c|c|c|c|}
\hline & Margin status & RT & $\mathrm{HR}^{\mathrm{a}}$ & T stage $\mathrm{e}^{\mathrm{b}}$ & N stage ${ }^{b}$ & Stage \\
\hline \multicolumn{7}{|c|}{ Margin status } \\
\hline $\mathrm{CC}^{\mathrm{c}}$ & 1 & 0.009 & 0.038 & 0.274 & 0.094 & 0.229 \\
\hline P-value & & 0.748 & 0.192 & 0 & 0.003 & 0 \\
\hline $\mathrm{N}^{\mathrm{d}}$ & 1390 & 1373 & 1185 & 952 & 963 & 953 \\
\hline \multicolumn{7}{|l|}{ RT } \\
\hline $\mathrm{CC}$ & 0.009 & 1 & 0.051 & 0.037 & 0.066 & 0.093 \\
\hline P-value & 0.748 & & 58.058 & 0.245 & 29.029 & 3.003 \\
\hline $\mathrm{N}$ & 1373 & 1722 & 1397 & 987 & 1086 & 1033 \\
\hline \multicolumn{7}{|l|}{ HR } \\
\hline $\mathrm{CC}$ & 0.038 & 0.051 & 1 & 0 & 0.025 & 0.042 \\
\hline P-value & 0.192 & 0.058 & & 0.991 & 0.447 & 0.204 \\
\hline $\mathrm{N}$ & 1185 & 1397 & 1424 & 876 & 947 & 914 \\
\hline \multicolumn{7}{|l|}{ T stage ${ }^{b}$} \\
\hline $\mathrm{CC}$ & 0.274 & 0.037 & 0 & 1 & 0.201 & 0.733 \\
\hline P-value & 0 & 0.245 & 0.991 & & 0 & 0 \\
\hline $\mathrm{N}$ & 952 & 987 & 876 & 987 & 986 & 987 \\
\hline \multicolumn{7}{|l|}{$\mathrm{N}$ stage $^{\mathrm{b}}$} \\
\hline $\mathrm{CC}$ & 0.094 & 0.066 & 0.025 & 0.201 & 1 & 0.785 \\
\hline P-value & 0.003 & 0.029 & 0.447 & 0 & _ & 0 \\
\hline $\mathrm{N}$ & 963 & 1086 & 947 & 986 & 1086 & 987 \\
\hline \multicolumn{7}{|l|}{ Stage $^{b}$} \\
\hline $\mathrm{CC}$ & 0.229 & 0.093 & 0.042 & 0.733 & 0.785 & 1 \\
\hline P-value & 0 & 0.003 & 0.204 & 0 & 0 & \\
\hline $\mathrm{N}$ & 953 & 1033 & 914 & 987 & 987 & 1033 \\
\hline
\end{tabular}

${ }^{\mathrm{a} H o r m o n e}$ responsiveness. ${ }^{\mathrm{b}}$ General Rules for Clinical and Pathological Recording of Breast Cancer (13th edition). ${ }^{\mathrm{c}}$ Pearson's correlation coefficient. ${ }^{\mathrm{d}}$ Number of available data.

Table V. Multivariate analyses.

\begin{tabular}{lccl}
\hline & RR & 95\% C.I. & P-value \\
\hline Margin status & 1.183 & $0.898-1.557$ & $\mathrm{P}=0.231$ \\
Radiation therapy & 0.227 & $0.168-0.307$ & $\mathrm{P}=0.000$ \\
T stage & 1.293 & $1.009-1.655$ & $\mathrm{P}=0.042$ \\
N stage & 1.867 & $1.508-2.312$ & $\mathrm{P}=0.000$ \\
Hormone receptor status & 0.796 & $0.615-1.029$ & $\mathrm{P}=0.082$ \\
\hline
\end{tabular}

Number of available data: 848 .

women $>70$ years of age who have early, estrogen-receptorpositive breast cancer with tamoxifen alone, rather than RT and tamoxifen, because the benefit of RT is still significant but very small (22). Thus, a subgroup of patients who have little or no benefit from RT has not been well defined yet. In Japan, however, whether to give RT after BCS remains controversial. Unfortunately, information regarding why RT was not given was not collected in this study; therefore, it cannot be rejected that a fear of radiation, which is characteristic of Japanese patients, caused them to decline $\mathrm{RT}$, but it is more likely that the presiding surgeons did not offer RT because they believed that the patient's risk of IBTR was low enough to omit RT or that the benefit of RT did not exceed its harm. Consequently, the subjects in this study might have a bias that patients who did not receive RT had an apparently lower risk of IBTR than patients who actually received RT. Therefore, the observed result that the ratio of patients who received RT was significantly lower in patients who eventually had IBTR duplicated existing clinical evidence. In addition, previous meta-analyses suggested that the addition of RT after BCS significantly improved overall survival $(5,23)$. Although the rationale for this observation was not fully explained, it is speculated that reduction of loco-regional recurrence leads to reduction of secondary dissemination to distant sites (23). Thus, omission of RT especially in young patients or patients with a high risk of IBTR, may deteriorate survival. Another interesting finding in this study is that the risk of IBTR is fairly constant over 
more than 10 years for both patients who received RT and who did not. Regular check-ups for IBTR may be necessary after 10 years.

Regarding the characteristics of IBTR, $68.6 \%$ occurred within or adjacent to the original tumor bed, which is similar to existing observations $(16,24,25)$. Of note, IBTR was salvaged with partial mastectomy in $48.6 \%$. Although data are sparse regarding the method of salvage surgery, partial mastectomy, which is equivalent to breast-conserving salvage surgery, seems higher than in existing studies (26-29). This might be related to the fact that 29\% (148/505) of patients had not received RT as initial treatment and RT can be administered safely after salvage surgery.

This study has several limitations. Almost all patients who developed IBTR in participating institutes were registered in this study; however, the completeness of registration for patients who did not develop IBTR is unknown in some institutes. Moreover, information regarding systemic adjuvant therapy and the details of RT were not collected for each patient; therefore, substantial bias may exists regarding systemic therapy and/or the radiation dose to the tumor bed between patients who had IBTR and patients who did not. This might have been why the margin status and young age, both of which are well known risk factors for IBTR, did not have a significant impact in this study. In other words, patients with unfavorable tumor factors who had RT may have had a better outcome than patients without unfavorable tumor factors who did not have RT. In conclusion, the results shown in this study, together with existing evidence, indicate that omission of RT after BCS is the most significant treatment factor related to IBTR. RT should be offered as standard for all patients who undergo BCS. Deterioration of local control and, possibly, overall survival should be discussed with patients before offering to omit RT.

\section{Acknowledgements}

Institutions contributing to this study: NTT West Kyoto Hospital, Uji Hospital, Kansai Medical University Otokoyama Hospital, Kyoto City Hospital, Kyoto Prefectural University of Medicine, Kinki University School of Medicine, Kinki-daigakuigakubu Nara Hospital, Kinki Central Hospital, Hyogo Prefectural Amagasaki Hospital, Kokawa Hospital, Himeji Medical Center, National Hospital Organization Osaka National Hospital, Saiseikai Nakatsu Hospital, Mitsubishi Kyoto Hospital, Sakai Municipal Hospital, Nagahama City Hospital, Toyonaka Municipal Hospital, Shiga Medical Center For Adults, Kobe City, General Hospital, Nishi-Kobe Medical Center, Ako City Hospital, Osaka Police Hospital, Osaka City University Hospital, Osaka Red Cross Hospital, Osaka University Hospital, Otsu Red Cross Hospital, Tenri Yorozu Soudansyo Hospital, Nara Medical University Hospital, Kodama Breast Clinic, Yao City Hospital, Hikone Municipal Hospital, St.Mary's Hospital, Osaka Medical Center For Cancer And Cardiovascular Diseases, Fukui Red Cross Hospital, Hyogo Prefectural Tsukaguchi Hospital and Yodogawa Christian Hospital.

\section{References}

1. Sonoo $\mathrm{H}$ and Noguchi S: Results of questionnaire survey on breast cancer surgery in Japan 2004-2006. Breast Cancer 15: 3-4, 2008.

2. Liljegren G, Holmberg L, Bergh J, et al: 10-Year results after sector resection with or without postoperative radiotherapy for stage I breast cancer: a randomized trial. J Clin Oncol 17: 2326-2333, 1999.

3. Veronesi U, Salvadori B, Luini A, et al: Breast conservation is a safe method in patients with small cancer of the breast. Long-term results of three randomised trials on 1,973 patients. Eur J Cancer 31A: 1574-1579, 1995

4. Malmstrom P, Holmberg L, Anderson H, et al: Breast conservation surgery, with and without radiotherapy, in women with lymph node-negative breast cancer: a randomised clinical trial in a population with access to public mammography screening. Eur J Cancer 39: 1690-1697, 2003.

5. Clarke M, Collins R, Darby S, et al: Effects of radiotherapy and of differences in the extent of surgery for early breast cancer on local recurrence and 15-year survival: an overview of the randomised trials. Lancet 366: 2087-2106, 2005.

6. Renton SC, Gazet JC, Ford HT, Corbishley C and Sutcliffe R: The importance of the resection margin in conservative surgery for breast cancer. Eur J Surg Oncol 22: 17-22, 1996.

7. Holli K, Saaristo R, Isola J, Joensuu H and Hakama M: Lumpectomy with or without postoperative radiotherapy for breast cancer with favourable prognostic features: results of a randomized study. Br J Cancer 84: 164-169, 2001.

8. Forrest AP, Stewart HJ, Everington D, et al: Randomised controlled trial of conservation therapy for breast cancer: 6-year analysis of the Scottish trial. Scottish Cancer Trials Breast Group. Lancet 348: 708-713, 1996.

9. Clark RM, Whelan T, Levine M, et al: Randomized clinical trial of breast irradiation following lumpectomy and axillary dissection for node-negative breast cancer: an update. Ontario Clinical Oncology Group. J Natl Cancer Inst 88: 1659-1664, 1996.

10. Fisher B, Anderson S, Bryant J, et al: Twenty-year follow-up of a randomized trial comparing total mastectomy, lumpectomy, and lumpectomy plus irradiation for the treatment of invasive breast cancer. N Engl J Med 347: 1233-1241, 2002.

11. Lazovich D, Solomon CC, Thomas DB, Moe RE and White E: Breast conservation therapy in the United States following the 1990 National Institutes of Health Consensus Development Conference on the treatment of patients with early stage invasive breast carcinoma. Cancer 86: 628-637, 1999.

12. Lim M, Bellon JR, Gelman R, et al: A prospective study of conservative surgery without radiation therapy in select patients with stage I breast cancer. Int J Radiat Oncol Biol Phys 65: $1149-1154,2006$

13. Chan A, Pintilie M, Vallis K, Girourd C and Goss P: Breast cancer in women $<$ or $=35$ years: review of 1002 cases from a single institution. Ann Oncol 11: 1255-1262, 2000.

14. Voogd AC, Peterse JL, Crommelin MA, et al: Histological determinants for different types of local recurrence after breastconserving therapy of invasive breast cancer. Dutch Study Group on local Recurrence after Breast Conservation (BORST). Eur J Cancer 35: 1828-1837, 1999.

15. de Bock GH, van der Hage JA, Putter H, Bonnema J, Bartelink H and van de Velde CJ: Isolated loco-regional recurrence of breast cancer is more common in young patients and following breast conserving therapy: long-term results of European Organisation for Research and Treatment of Cancer studies. Eur J Cancer 42: 351-356, 2006.

16. Gage I, Recht A, Gelman R, et al: Long-term outcome following breast-conserving surgery and radiation therapy. Int J Radiat Oncol Biol Phys 33: 245-251, 1995.

17. Matthews RH, McNeese MD, Montague ED and Oswald MJ: Prognostic implications of age in breast cancer patients treated with tumorectomy and irradiation or with mastectomy. Int $\mathrm{J}$ Radiat Oncol Biol Phys 14: 659-663, 1988.

18. Nixon AJ, Neuberg D, Hayes DF, et al: Relationship of patient age to pathologic features of the tumor and prognosis for patients with stage I or II breast cancer. J Clin Oncol 12: 888-894, 1994.

19. Kurtz JM, Jacquemier J, Amalric R, et al: Why are local recurrences after breast-conserving therapy more frequent in younger patients? J Clin Oncol 8: 591-598, 1990.

20. Fisher B, Dignam J, Bryant J, et al: Five versus more than five years of tamoxifen therapy for breast cancer patients with negative lymph nodes and estrogen receptor-positive tumors. J Natl Cancer Inst 88: 1529-1542, 1996. 
21. Fisher B, Dignam J, Mamounas EP, et al: Sequential methotrexate and fluorouracil for the treatment of node-negative breast cancer patients with estrogen receptor-negative tumors: eight-year results from National Surgical Adjuvant Breast and Bowel Project (NSABP) B-13 and first report of findings from NSABP B-19 comparing methotrexate and fluorouracil with conventional cyclophosphamide, methotrexate, and fluorouracil. J Clin Oncol 14: 1982-1992, 1996.

22. Hughes KS, Schnaper LA, Berry D, et al: Lumpectomy plus tamoxifen with or without irradiation in women 70 years of age or older with early breast cancer. N Engl J Med 351: 971-977, 2004.

23. Vinh-Hung V and Verschraegen C: Breast-conserving surgery with or without radiotherapy: pooled-analysis for risks of ipsilateral breast tumor recurrence and mortality. J Natl Cancer Inst 96: 115-121, 2004.

24. Krauss DJ, Kestin LL, Mitchell C, Martinez AA and Vicini FA Changes in temporal patterns of local failure after breastconserving therapy and their prognostic implications. Int J Radiat Oncol Biol Phys 60: 731-740, 2004.
25. Komoike Y, Akiyama F, Iino Y, et al: Analysis of ipsilateral breast tumor recurrences after breast-conserving treatment based on the classification of true recurrences and new primary tumors. Breast Cancer 12: 104-111, 2005

26. Kurtz JM, Jacquemier J, Amalric R, et al: Is breast conservation after local recurrence feasible? Eur J Cancer 27: 240-244, 1991.

27. Voogd AC, van Tienhoven G, Peterse HL, et al: Local recurrence after breast conservation therapy for early stage breast carcinoma: detection, treatment, and outcome in 266 patients. Dutch Study Group on Local Recurrence after Breast Conservation (BORST). Cancer 85: 437-446, 1999.

28. Salvadori B, Marubini E, Miceli R, et al: Reoperation for locally recurrent breast cancer in patients previously treated with conservative surgery. Br J Surg 86: 84-87, 1999.

29. Alpert TE, Kuerer HM, Arthur DW, Lannin DR and Haffty BG: Ipsilateral breast tumor recurrence after breast conservation therapy: outcomes of salvage mastectomy vs. salvage breastconserving surgery and prognostic factors for salvage breast preservation. Int J Radiat Oncol Biol Phys 63: 845-851, 2005. 